\title{
Oil Speculation and Herding Behavior in Emerging Stock Markets
}

\author{
Esin Cakan \\ Department of Economics, University of New Haven, CT 06516, USA. \\ Rıza Demirer \\ Department of Economics \& Finance, Southern Illinois University Edwardsville, Edwardsville, IL 62026-1102, \\ USA. \\ Rangan Gupta \\ Department of Economics, University of Pretoria, Pretoria, South Africa. \\ Hardik A. Marfatia \\ Department of Economics, Northeastern Illinois University, Chicago, IL 60025, USA.
}

\begin{abstract}
This paper explores the relationship between stock and commodity markets from a novel perspective by examining the relationship between speculation in the oil market and investor herding in stock markets. Using firm level data from three energy importing and exporting nations, namely Russia, Brazil, and Turkey, we show that these markets often switch between herding and anti-herding states, while herding is more prevalent in the case of Russia. We also find that speculative activities in the global oil market significantly affect investors behavior in Russia and Brazil with greater oil speculation associated with herding in these markets. Our findings suggest that policy makers should watch measures of speculative activities in the commodity markets for possible signals in order to model and monitor investor behavior in their local markets.
\end{abstract}

JEL Classification Code: G14, G15

Keywords: Emerging markets; Herd behavior; Crude Oil; Speculative ratio. 


\section{Introduction}

Investor behavior in financial markets has been studied extensively in the literature, particularly following the recent financial market crises and subsequent volatility spillovers across global financial markets. With an increased interest on periods of market stress and how such periods affect stock market movements, a number of papers have recently been published focusing on herd behavior among investors. While most of these studies document evidence of investor herding, particularly in emerging stock markets and more prevalently during periods of market stress (e.g. Balcilar et al., 2013; Babalos et al., 2013; Yao et al., 2014; Balcilar and Demirer, 2015), a research question is whether certain global proxies of market stress can explain the evolution of herding or anti-herding in stock markets. If one can identify such global proxies of market stress that significantly influence investors' behavior, particularly in emerging markets, then regulators in those countries can focus on those stress proxies in order to develop safety nets and circuit breakers. This may help prevent the destabilizing effects of investor herding as herd behavior plays a role in affecting market volatility and pricing inefficiencies (e.g. Bikhchandani and Sharma, 2000; Blasco et al, 2012).

The literature generally suggests that herd behavior is more prevalent during periods of market stress or unusual market movements. The most important drawback of this aggregated irrationality is that herd behavior may exacerbate volatility, destabilize markets, increase the fragility of the financial system (see, Bikhchandani and Sharma, 2000), and negatively impact rational portfolio management. Rising inefficiency and financial fragility through herding may eventually trigger financial crisis during market turbulences.

This study aims to provide a novel insight to the evolution of herd behavior during crisis periods by relating the time variation in the level of investor herding to speculation in the oil 
market, a widely traded commodity considered a feedstock that affects production costs and economic growth expectations. As Kilian (2008) notes, exogenous oil supply shocks may cause a sharp drop in real GDP growth rather than an immediate and sustained reduction in economic growth and a spike in CPI inflation. Furthermore, as Bernanke (2016) suggests, stock and oil markets tend to move together recently as they both react to a common factor, reflecting softening of global aggregate demand. To that end, it can be argued that speculative dynamics in the oil market may contain valuable information regarding global economic fundamentals, and thus, the performance of financial markets globally. Therefore, the contribution of this study is to relate speculative dynamics in the oil market to financial markets from a behavioral perspective by examining its possible relationship to investors' herding or anti-herding patterns.

Our empirical analysis focuses on three important emerging markets, namely Turkey, Brazil and Russia, that can be argued to be highly sensitive to global commodity prices. Russia is one of the major oil exporting nations globally, the second largest oil exporter after Saudi Arabia (CIA World Fact book). Its exports rose 5\% to 5.55 million barrels a day in the first half of 2016 from the same period in 2015, while its output in June climbed 1.14 percent from a year earlier to 10.843 million barrels a day, with increases every month since July 2014, according to data from the Energy Ministry. Similarly, Brazil is among the largest export economies in the world with crude oil being one of its top exports. However, oil market sensitivity for this country is not as straightforward to explain as its crude oil exports are matched with imports of refined petroleum ( $\$ 8.04$ billion), crude petroleum ( $\$ 6.55$ billion $)$, and petroleum Gas ( $\$ 5.56$ billion) in 2015 .

On the other hand, Turkey is the emerging nation in the sample on the importer side marked by its heavy dependence on energy imports, which account for about $74 \%$ of its energy 
use. ${ }^{1}$ Furthermore, the high level of private/state sector borrowing requirements and its current account deficit pose further structural risks, potentially making its economy highly sensitive to global commodity prices. Brazil and Turkey have historically been affected from oil shocks more than Russia. To that end, one can argue that the investor behavior in these three markets can exhibit markedly different characteristics under a possible oil shock as they have heterogeneous sensitivities to global oil prices. It is possible that oil shocks may trigger interest among investors domestically and otherwise, potentially contributing to the presence of herding through correlated trades. Recognizing that this question can be answered empirically at best, oil importer and exporter emerging markets provide an interesting avenue to examine herd behavior.

In addition to its contribution to the herding literature, this study also contributes to the strand of the literature that deals with the relationship between commodities and stock markets. Several papers have documented that commodities like gold and oil can help forecast real exchange rates in major commodity exporters (e.g., Apergis, 2014). To that end, relating speculation in the market for oil to investor behavior in these major emerging stock markets can enlarge our understanding of how commodity market dynamics relate to stock market dynamics in major exporting nations. Finally, a third contribution of this study is from an econometric perspective in that we model time variations that not only reveal different periods during which herding or anti-herding may be present, but also directly relates the speculative ratio in the oil market to herding. By doing so, this study contributes both to the herding literature and to the literature on the relationship between commodity and stock markets.

Our findings suggest that these emerging markets experience periods of herding and anti-herding with a more prevalent herding pattern observed in the case of Russia. While the tests

\footnotetext{
${ }^{1}$ The World Bank Open Data. http://data.worldbank.org.
} 
for the whole sample period indicate the presence of herding in all three markets, considering possible structural breaks implied by Bai and Perron (2003) structural break tests, we observe that the market switches between herding and anti-herding states, particularly in Brazil and Russia. While herding in Brazil is mostly concentrated in periods following the global financial crisis of 2007/2008, we see that it is more prevalent in Russia, during most of the subsamples examined.

Examining the relationship between the time-variation in herding in these emerging markets to the level of speculation in the oil market, we find that herding in Russia and Brazil are significantly affected by oil market speculation such that greater oil speculation is associated with herding in these markets. We argue that investors see high level of speculative activities in the oil market as a sign of increased uncertainty regarding the direction of global demand and thus display greater tendency to go with the market consensus, i.e. herd, in order to ride the wave of uncertainty. Our findings suggest that policymakers should watch measures of speculative activities in the commodity markets for possible signals in order to monitor potential effects of global shocks in their local markets.

The rest of this paper is organized as follows. Section 2 briefly summarizes the literature on herding tests in stock markets and the oil-stock market relationship in the oil export-import country context. Section 3 presents the data and methodology. Section 4 provides the empirical findings and Section 5 concludes the paper.

\section{Literature Review}

The importance of oil price and its influence on the economy has been studied immensely in the literature (e.g., Jones et al, 2004, Basher and Sadorsky, 2006; Kilian, 2008, Kilian and Park, 2009, Issac and Ratti, 2009, Apergis and Miller, 2009, Arouri and Rault, 2011, Sukcharoen 
et al., 2014, among others). For example, Jones et al (2004) find that there is a stable nonlinear relationship between oil price shocks and GDP and the division of responsibility for post-oilprice shock recessions between monetary policy and oil price shocks, has leaned heavily toward oil price shocks. Arouri and Rault (2011) also find evidence for cointegration between oil prices and stock markets in GCC countries. However, using copula models, Sukcharoen et al. (2014) argue that only a weak dependence between oil prices and stock indices is present in the case of several countries, except United States and Canada.

Looking at the literature of herding, as mentioned earlier, the strand of the literature on investor herding has experienced a surge in published papers, particularly following the 2007/2008 global financial crisis. Some of the pioneering works in this field include Christie and Huang (1995) and Chang et al. (2000) who propose a return dispersion based methodology detect the presence of herding. ${ }^{2}$ These herding tests that focus on the cross-sectional behavior of firm returns within portfolios consisting firms of similar characteristics have been applied to numerous advanced and emerging stock markets and in different variations of model specifications. Some of the well-cited applications of these tests include Demirer and Kutan (2006), Tan et al. (2008), Yao et al. (2014), and Demirer et al. (2015) on Chinese stocks and industries; Chiang and Zheng (2010) on a collection of advanced and emerging stock markets; Economou et al. (2011) on southern European stock markets; Balcilar et al. $(2013,2014)$ on the emerging and frontier Gulf Arab stock markets; Philippas et al. (2013) on real estate investment trusts; Balcilar and Demirer (2015); and Cakan and Balagyozyan (2014) on the Turkish stock market; among others.

\footnotetext{
${ }^{2}$ Demirer et al. (2010) provide a review of the different testing methodologies based on return dispersion.
} 
Recognizing the weakness of the benchmark herding models in Christie and Huang (1995) and Chang et al. (2000) that assume constant parameters, and thus fail to account for the dynamic market states during which herding may or may not be present, recent works including Balcilar et al. (2013, 2014) and Balcilar and Demirer (2015) have proposed dynamic specifications that are based on Markov switching rolling regression. The evidence from these studies imply a link between crisis periods and investor herding, confirming earlier arguments that herding is more prevalent during periods of market stress (e.g. Christie and Huang, 1995; Bikhchandani and Sharma, 2001). However, none of these studies has employed rolling regressions to relate the time-variation in herding to oil speculation in order to trace the evolution of herding or anti-herding over time. To that end, an econometric contribution of this study is to extend the literature to a rolling regression specification and use this specification to relate the time-variation in herding to speculative activities in oil, that is long considered a volatile market during periods of market crisis.

Although oil-stock market relationship has been heavily examined in the literature, how this interaction plays out in a behavioral context is largely unexplored and the three emerging markets examined in this study, Russia, Brazil and Turkey, present an interesting combination as they represent the different ends of the oil-stock market nexus. Russia is one of the largest oil exporter globally in 2016 and oil income is the driving source of its economy. Crude oil is considered one of the most traded commodity globally and has experienced tremendous volume of trading activity, of which a significant proportion is linked to speculation. Therefore, speculation in this commodity, particularly during stock market turbulences, given Russia's heavy dependence on oil exports, and Turkey and Brazil's sensitivity to global commodity prices, speculative activities in this commodity can be expected to influence investor behavior in 
these emerging markets via multiple channels with significant implications on portfolio hedging and exchange rate risk management.

\section{Data and methodology}

\subsection{Data}

We employ daily closing prices for all stocks traded in Turkey (BIST), Russia (MICEX) and Brazil (BOVESPA) stock exchanges over the period of 10/28/2005 - 10/29/2015, including 2,610 observations. We obtain the data from Datastream and the selection criterion of the firms is based on the availability of data. We calculate daily returns for stocks (in domestic currency) as the first difference of the natural logarithm of the stock price. Oil returns are calculated using the Brent crude oil price as this type of oil represents the global benchmark (Balcilar et al., 2017). In addition to the tests over the whole sample period, we also perform a sub-period analysis following the break dates based on Bai and Perron (2003) structural break tests. The details of the sub-periods are provided in Table 1. We measure oil speculation using the speculative ratio of Chan et al. (2015), which is defined as the trading volume divided by open interest on a given day. We calculate this ratio using daily data on trading volume and open interest for Brent oil futures contracts traded on the Chicago Mercantile Exchange, with the data obtained from Commodity Systems Inc. 
Table 1: Estimates for the benchmark herding model.

\begin{tabular}{|c|c|c|c|c|}
\hline & & Brazil & Russia & Turkey \\
\hline \multirow{3}{*}{ Full sample } & $\alpha_{0}$ & 1.830 **** & $2.236 * * *$ & $2.028 * * *$ \\
\hline & $\alpha_{1}$ & $1.721 * * *$ & $1.541 * * *$ & $0.420 * * *$ \\
\hline & $\alpha_{2}$ & $-0.092 * * *$ & $-0.062 * * *$ & $-0.021 * * *$ \\
\hline \multirow{5}{*}{ Sub-sample 1} & & $(2005 / 10 / 31-$ & $(2005 / 10 / 31-$ & $(2005 / 10 / 31-$ \\
\hline & & 2007/07/12) & 2006/03/17) & $2008 / 01 / 01)$ \\
\hline & $\alpha_{0}$ & $2.178 * * *$ & $1.866 * * *$ & $1.983 * * *$ \\
\hline & $\alpha_{1}$ & $0.671 * *$ & $2.372 * * *$ & $0.327 * * *$ \\
\hline & $\alpha_{2}$ & $0.872 * * *$ & $-0.186 * * *$ & -0.010 \\
\hline \multirow{4}{*}{ Sub-sample 2} & & $\begin{array}{l}(2007 / 07 / 13- \\
2009 / 07 / 08)\end{array}$ & $\begin{array}{l}(2006 / 03 / 18- \\
2010 / 08 / 31)\end{array}$ & $\begin{array}{c}(2008 / 01 / 02- \\
2009 / 07 / 01)\end{array}$ \\
\hline & $\alpha_{0}$ & $2.429 * * *$ & $1.481^{* * *}$ & $2.500 * * *$ \\
\hline & $\alpha_{1}$ & $1.050 * * *$ & $1.612 * * *$ & $0.285^{* * *}$ \\
\hline & $\alpha_{2}$ & -0.030 & $-0.054 * * *$ & -0.006 \\
\hline \multirow{4}{*}{ Sub-sample 3} & & $\begin{array}{c}(2009 / 07 / 09- \\
2011 / 01 / 07)\end{array}$ & $\begin{array}{c}(2010 / 09 / 01- \\
2010 / 05 / 03)\end{array}$ & $\begin{array}{l}(2009 / 07 / 02- \\
2010 / 12 / 31)\end{array}$ \\
\hline & $\alpha_{0}$ & $1.493 * * *$ & $2.610 * * *$ & $1.980 * * *$ \\
\hline & $\alpha_{1}$ & $1.953 * * *$ & $1.102 * * *$ & $0.715^{* * *}$ \\
\hline & $\alpha_{2}$ & $-0.621 * *$ & 0.038 & $-0.078 * * *$ \\
\hline \multirow{4}{*}{ Sub-sample 4} & & $\begin{array}{c}(2011 / 01 / 10- \\
2012 / 07 / 09)\end{array}$ & $\begin{array}{c}(2010 / 05 / 04- \\
2012 / 09 / 11)\end{array}$ & $\begin{array}{l}(2011 / 01 / 03- \\
2012 / 07 / 02)\end{array}$ \\
\hline & $\alpha_{0}$ & $1.546 * * *$ & $1.581 * * *$ & $2.224 * * *$ \\
\hline & $\alpha_{1}$ & $2.031 * * *$ & $1.772 * * *$ & $0.211 * * *$ \\
\hline & $\alpha_{2}$ & $-0.349 * * *$ & $-0.217 * * *$ & -0.003 \\
\hline \multirow{4}{*}{ Sub-sample 5} & & $\begin{array}{c}(2012 / 07 / 10- \\
2014 / 01 / 07)\end{array}$ & $\begin{array}{c}(2012 / 09 / 12- \\
2014 / 02 / 10)\end{array}$ & $\begin{array}{l}(2012 / 07 / 03- \\
2014 / 04 / 23)\end{array}$ \\
\hline & $\alpha_{0}$ & $1.828 * * *$ & $2.379 * * *$ & $1.729 * * *$ \\
\hline & $\alpha_{1}$ & $0.920 * *$ & $2.052 * * *$ & $0.408 * * *$ \\
\hline & $\alpha_{2}$ & $0.874 * * *$ & $-0.273 * * *$ & $-0.017 * *$ \\
\hline \multirow{4}{*}{ Sub-sample 6} & & $\begin{array}{l}(2014 / 01 / 08- \\
2015 / 10 / 28)\end{array}$ & $\begin{array}{l}(2014 / 02 / 10- \\
2015 / 10 / 28)\end{array}$ & $\begin{array}{l}(2014 / 04 / 24- \\
2015 / 10 / 28)\end{array}$ \\
\hline & $\alpha_{0}$ & $1.892 * * *$ & $2.896 * * *$ & $2.069 * * *$ \\
\hline & $\alpha_{1}$ & $1.945 * * *$ & $1.528 * * *$ & $0.364 * * *$ \\
\hline & $\alpha_{2}$ & $-0.419^{*}$ & $-0.106^{* * *}$ & -0.003 \\
\hline
\end{tabular}

Note: The table presents the estimates of the model $\operatorname{CSSD}_{t}=\alpha_{0}+\alpha_{1}\left|R_{m, t}\right|+\alpha_{2} R_{m, t}^{2}+\varepsilon_{t}$ for full sample period as well as the model with the structural breaks along with the break dates. These results reveal the statistical significance and the degree herding $\left(\alpha_{2}<0\right)$ or anti-herding $\left(\alpha_{2}>0\right)$. '***', '**', '*' indicates significance at 1,5 and $10 \%$, respectively. 


\subsection{Methodology}

The methodology to detect herding follows number of studies including Chang et al. (2000), Tan et al. (2008), Demirer et al. (2010, 2014), Chiang and Zheng (2010), Economou et al. (2011), Balcilar et al. (2013, 2014, 2017), Babalos et al. (2013, 2015) and Balcilar and Demirer (2015), among others. Originally, developed by Christie and Huang (1995) and later improved by Chang et al. (2000), the test employs return data across securities of similar characteristics. Unlike other herding tests that require transaction or holding data which is often available at quarterly basis, the use of daily return data in this particular methodology allows us to trace the time-variation in herding to gold market dynamics and is preferable in the particular context of this study.

The benchmark model is developed from the CAPM specification of returns and uses the deviations from the CAPM to make inferences on the presence of herding. The test focuses on the cross-sectional absolute deviation of returns (CSAD) expressed as

$$
C S A D_{t}=\frac{1}{N} \sum_{i=1}^{N}\left|R_{i, t}-R_{m, t}\right|
$$

where $N$ is the number of firms in each country stock market, $R_{i, t}$ is the observed return on the firm, $i$ for day $t$ and $R_{m, t}$ is the return on the market portfolio for day $t$. One can then show that expected CSAD should, in theory, have a non-negative relation with the expect market return, implied by a non-negative first derivative with respect to expected market return, while the second derivative with respect to the market return is zero. This implies that greater crosssectional dispersion in asset returns should, in theory, be expected for larger market movements and the relationship between market return and cross-sectional return dispersion should be linear. 
On the other hand, according to the CAPM specification, the second derivative of the CSAD term with respect to market return is expected to be zero, indicating a linear relationship between asset betas and expected returns. As a result, using the CAPM specification of returns as a basis, Chang et al. (2000) propose the following quadratic benchmark model

$$
\operatorname{CSAD}_{t}=\alpha_{0}+\alpha_{1}\left|R_{m, t}\right|+\alpha_{2} R_{m, t}^{2}+\varepsilon_{t}
$$

where a significant and negative estimate for $\alpha_{2}$ is used as support for the presence of herding. As the herding test in Equation 2 is based on the coefficient of the non-linear term, we focus on the herding coefficient, $\operatorname{herd}_{t}\left(\alpha_{2}\right)$, as a proxy for the level of herding in the market so that increasingly negative values for the herding coefficient indicate higher degree of herding.

Notice that the estimates of the fixed-coefficient model of equation (2) would reveal only the average herding behavior. In the presence of structural changes in the financial markets, the dynamic behavior of herding would remain uncovered. To meet this objective, we estimate Equation 2 using Bai and Perron (2003) structural break methodology. This procedure uncovers the precise dates when the break occurred in the relationship and also reveals the changing nature of the estimates between sub-samples. For our case, we use the powerful UDMax and WDMax test statistics based on 1 to $M$ globally determined breaks and allowing for error distributions to differ across the breaks. Furthermore, to uncover the time-varying evolution of the herding process, we estimate a rolling regression of the model, based on a window of 250 observations, which in turn, are smaller than the size of the first break date in each country. This framework has the additional advantage of providing us the flexibility to measure the possible impact of oil market speculation and volatility on the herding process. 
Following the argument by Froot et al. (1992) of a possible link between speculative activities and investor herding and the evidence by Balcilar et al. $(2013,2014)$ that herding and market volatility are closely related, we conjecture that the intensity of herding measured by the coefficient $\alpha_{2}$ in Equation 2 is likely to depend on the level of speculative activity as well as market volatility. Therefore, we extend the model and allow the intensity of herding to depend on the speculative activity and market volatility.

In order to estimate the impact of speculative activity and market volatility, we estimate the following model:

$$
\operatorname{herd}_{t}=\beta_{0}+\beta_{1} \text { oil }_{t}+\omega_{t}
$$

where, oil $t_{t}$ captures the oil speculation ratio in each country and $h e r d_{t}$ is the estimated herding coefficient from Equation (2). In Equation (3) the parameter of interest is $\beta_{1}$ as it captures the extent to which the speculation in the oil prices impacts the degree of herding. Since it is likely that the oil speculation may impact herding behavior differently across time, we also test for structural break in the above model.

The sign of the coefficient $\beta_{1}$ which caputers the impact of oil speculation on the investor herding behavior can take both positive as well as negative value. The coefficient can take positive value when greater speculation in the oil market is typically associated with economic downturns and higher financial market volatility. The heightened uncertainty in the markets makes the prediction of future market movements increasingly difficult. As a result, investors are more like to follow a herding process. This intuition is also supported in the literature where Balcilar et al. (2013, 2014), for example, find that the effects of gold speculation on the investor herding behavior is regime dependent in that the speculative activities in the gold market impact herding during the high volatility market state. The intuition of the negative value of the 
coefficient $\beta_{1}$ is possibly driven by the oil speculation acting as a signal for the state of the financial markets. A lower speculation would imply easier processing of the information and consequently, promoting the herding process.

\section{Estimation Results}

\subsection{Benchmark herding tests}

Table 1 presents the results of the herding tests based on the benchmark model presented in Equation 2. Looking at the full sample results, the test results suggest that herding is present in all three emerging markets, indicated by the significant and negative herding coefficients $\left(\alpha_{2}\right)$ for all three countries. This is consistent with the earlier findings for other emerging markets where herding is found to be significant (e.g. Balcilar et al, 2016). However, examining the subsamples based on Bai and Perron (2003) structural break tests, we observe that these markets experience episodes of herding and anti-herding, particularly in the case of Brazil. We see that herding in Brazil is mostly concentrated in periods following the global financial crisis of 2007/2008, while it is more prevalent in Russia as indicated by highly significant and negative herding coefficients for all but one subsample.

These observations are further elaborated in Figure 1 where we present the time-varying herding coefficients estimated from the rolling regressions. Examining the figure for Brazil, for example, we see that the market was largely in an anti-herding state during the run-up to the global financial crisis and later in 2013. It is possible that the commodity market boom experienced prior to the global financial crisis led investors in this major commodity-exporting nation to take on speculative positions by going against the crowd in their stock market. On the 

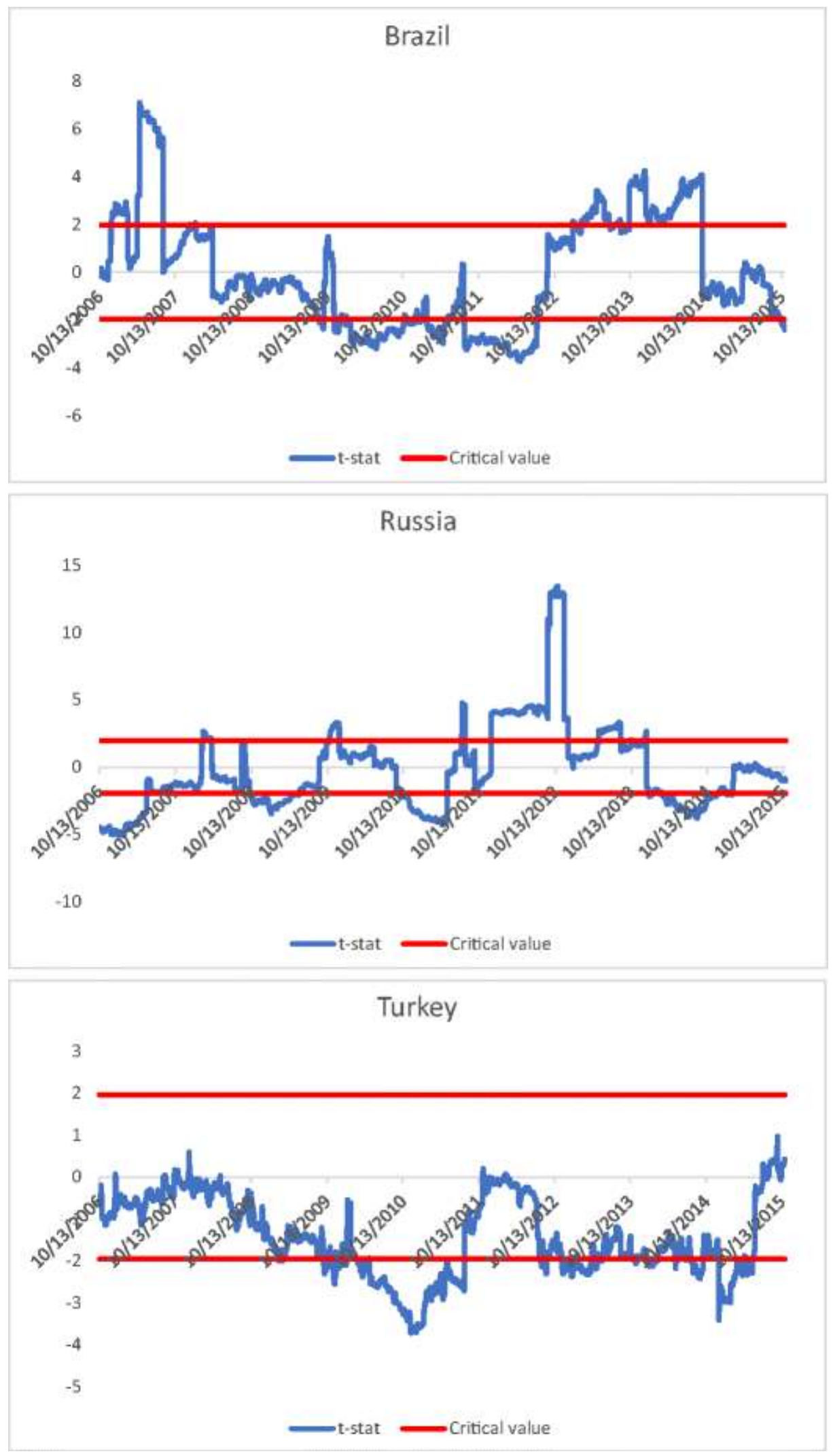

Figure 1: Time-varying herding coefficients from rolling regressions . 
other hand, we see that the picture is quite different for Turkey where the estimated herding coefficients are mostly in the negative territory, implying the prevalence of herding, particularly following the global crisis and into 2010. Russia, however, behaves somewhat similar to Brazil in that we see evidence of switches from herding to anti-herding, with marked anti-herding during 2012 when Russia had its presidential elections. It is also interesting that the Russian market experienced a brief episode of herding during 2014 when Russia annexed Crimea and its buildup of military forces on the Ukrainian border for a possible incursion into this country posed significant geopolitical risks for the region.

Overall, the estimates from the benchmark herding tests suggest that all three markets experienced significant herding in their stock markets during the sample period. However, the time-varying herding coefficients indicate that these markets often switch between herding and anti-herding states, particularly in the case of Russia and Brazil. We next examine whether the time variation in herding relates to the level of speculation in the global oil market.

\subsection{Benchmark herding tests}

Table 2 presents the results for the effect of oil speculation on herding as shown in Equation 3. As mentioned earlier, we measure oil speculation using the speculative ratio of Chan et al. (2015), which is defined as the trading volume divided by open interest on a given day. Chan et al. (2015) argue that a lower ratio of trading volume to open interest implies lower speculative activity relative to hedging as hedgers would be likely to obtain more long positions in the futures market if they see a potential positive price movement in order to better cover their underlying positions. This, in turn, would lead to a large increase in open interest relative to trading volume, thus yielding a lower speculative ratio. We calculate this ratio using daily data 
on trading volume and open interest for Brent oil futures contracts traded on the Chicago Mercantile Exchange.

Table 2: The effect of oil speculation herding.

\begin{tabular}{|c|c|c|c|c|}
\hline & & Brazil & Russia & Turkey \\
\hline \multirow{2}{*}{ Full sample } & $\beta_{0}$ & $0.466 * * *$ & $-0.047 * *$ & $-0.047 * * *$ \\
\hline & $\beta_{1}$ & $-1.032 * * *$ & $-0.066^{*}$ & 0.002 \\
\hline \multirow{4}{*}{ Sub-sample 1} & & $(2006 / 10 / 13-$ & $(2005 / 10 / 31-$ & $(2006 / 10 / 13-$ \\
\hline & & 2008/02/19) & $2006 / 03 / 17)$ & $2008 / 06 / 27)$ \\
\hline & $\beta_{0}$ & $0.528 * *$ & $0.999 * * *$ & $-0.008 * * *$ \\
\hline & $\beta_{1}$ & $-0.383 * * *$ & -0.115 & $0.007 * * *$ \\
\hline \multirow{3}{*}{ Sub-sample 2} & & $\begin{array}{c}(2008 / 02 / 20- \\
2009 / 11 / 13)\end{array}$ & $\begin{array}{c}(2006 / 03 / 18- \\
2010 / 08 / 31)\end{array}$ & $\begin{array}{c}(2008 / 06 / 30- \\
2009 / 11 / 04)\end{array}$ \\
\hline & $\beta_{0}$ & -0.019 & -0.069 & $-0.019 * * *$ \\
\hline & $\beta_{1}$ & -0.006 & -0.015 & 0.005 \\
\hline \multirow{3}{*}{ Sub-sample 3} & & $\begin{array}{c}(2009 / 11 / 16- \\
2011 / 07 / 22)\end{array}$ & $\begin{array}{c}(2010 / 09 / 01- \\
2010 / 05 / 03)\end{array}$ & $\begin{array}{c}(2009 / 11 / 05- \\
2011 / 03 / 15)\end{array}$ \\
\hline & $\beta_{0}$ & $-0.124 * * *$ & $0.145^{* *}$ & $-0.098 * * *$ \\
\hline & $\beta_{1}$ & $-0.665 * * *$ & $-0.099 *$ & $0.043 * * *$ \\
\hline \multirow{3}{*}{ Sub-sample 4} & & $\begin{array}{c}(2011 / 07 / 25- \\
2012 / 11 / 28)\end{array}$ & $\begin{array}{c}(2010 / 05 / 04- \\
2012 / 09 / 11)\end{array}$ & $\begin{array}{c}(2011 / 03 / 16- \\
2012 / 07 / 20)\end{array}$ \\
\hline & $\beta_{0}$ & $-0.082 *$ & $-0.270 * * *$ & $-0.013 * * *$ \\
\hline & $\beta_{1}$ & $-0.219 * *$ & -0.002 & $-0.013 *$ \\
\hline \multirow{3}{*}{ Sub-sample 5} & & $\begin{array}{c}(2012 / 11 / 29- \\
2014 / 06 / 20)\end{array}$ & $\begin{array}{c}(2012 / 09 / 12- \\
2014 / 02 / 10)\end{array}$ & $\begin{array}{c}(2012 / 07 / 23- \\
2013 / 11 / 27)\end{array}$ \\
\hline & $\beta_{0}$ & $0.720 * * *$ & -0.218 & $-0.115 * * *$ \\
\hline & $\beta_{1}$ & -0.071 & $-0.093 * * *$ & 0.008 \\
\hline \multirow{3}{*}{ Sub-sample 6} & & $\begin{array}{c}(2014 / 06 / 23- \\
2015 / 10 / 28)\end{array}$ & $\begin{array}{c}(2014 / 02 / 10- \\
2015 / 10 / 28)\end{array}$ & $\begin{array}{c}(2013 / 11 / 28- \\
2015 / 10 / 28)\end{array}$ \\
\hline & $\beta_{0}$ & $-0.340 * * *$ & $-0.097 * * *$ & $-0.033 * * *$ \\
\hline & $\beta_{1}$ & $0.815^{* * *}$ & $-0.072 * * *$ & $-0.052 * *$ \\
\hline
\end{tabular}

Note: The table presents the estimates of the model herd ${ }_{t}=\beta_{0}+\beta_{1}$ oil $_{t}+\omega_{t}$ for full sample period as well as the model with the structural break along with the break dates. These results reveal the statistical significance and the degree to which the herding / anti-herding is driven by oil speculation. ' $* * *$ ', '**', '*' indicates significance at 1,5 and $10 \%$, respectively.

Examining the full sample results, we observe that only Brazil and Russia are significantly affected by the level of oil speculation. This is in fact consistent with the plots for these two countries in Figure 1, which suggests a greater degree of time-variation in the level of herding in these markets. Interestingly however, we observe significant and negative estimates 
for $\beta_{1}$, implying that greater level of speculation in the global oil market is associated with lower values for the herding coefficient, implying greater herding. This finding suggests that speculative activities in the global oil market indeed contain significant information that affects investor behavior in these emerging economies. Considering the finding that higher level of speculation in the oil market is associated with greater level of herding (i.e. lower values for the herding coefficient), it is possible that investors see greater speculative activity in the oil market as a sign of greater uncertainty in the oil market, and thus global economic expectations, resulting in a greater tendency to go with the market consensus. Once again, this pattern is most prevalent in the case of Russia and partially for Brazil, while we do not observe a consistent oil speculation effect on investor behavior in the case of Turkey.

Overall, our findings suggest that the level of speculation in the global oil market contains information that affects investor behavior particularly in Russia and Brazil. Higher level of speculation in oil is associated with greater degree of herding in these countries, suggesting that policymakers should add measures of commodity market speculation to their list of variables to watch out, as speculation in the commodity market could provide valuable information regarding expected investor behavior in emerging stock markets.

\section{Conclusion}

This paper explores the relationship between stock and commodity markets from a novel perspective by examining the relationship between the level of speculation in commodity markets and investor herding in stock markets. Using firm-level data from three emerging markets, i.e. Brazil, Russia and Turkey, we show that these markets indeed experience periods of herding and anti-herding with more prevalent herding observed in the case of Russia. Relating the time-variation in herding to the level of speculation in the oil market, we find that Russia and 
Brazil experience herding during periods of high speculative activities in the global oil market.

We argue that investors see high level of speculative activities in the oil market as a sign of increased uncertainty regarding the direction of global demand, and thus display greater tendency to go with the market consensus, i.e. herd, in order to ride the wave of uncertainty. Our findings suggest that the level of speculation in commodity markets contain valuable information that drives investor behavior in emerging markets, and thus must be considered in modeling and monitoring investor dynamics in these markets.

\section{References}

Apergis, N. 2014. Can gold prices forecast the Australian dollar movements? International Review of Economics and Finance 29, 75-82.

Apergis, N. and Miller, S.M. (2009). Do structural oil - market shocks affect stock prices? Energy Economics, 31(4), 569-575.

Arouri, M., Jouini, J., Nguyen, D. K., 2011. Volatility spillovers between oil prices and stock sector returns: Implications for portfolio management. Journal of International Money and Finance, 30, 1387-1405.

Babalos, V., Economou, F., Kostakis, A., \& Philippas, N. 2013. Herding Behaviour in REITs: Novel Tests and the Role of Financial Crisis. International Review of Financial Analysis, 29, 166-174.

Bai, J. \& Perron, P., 2003. Computation and analysis of multiple structural change models," Journal of Applied Econometrics, 18(1), 1-22.

Balcilar, M., Demirer, R., Hammoudeh, S. 2013. Investor herds and regime-switching: Evidence from Gulf Arab stock markets. Journal of International Financial Markets, Institutions \& Money 23, 295-321.

Balcilar, M., Demirer, R., and Hammoudeh, S. 2014. What Drives Herding in Developing Stock Markets? Relative Roles of Own Volatility and Global Factors. North American Journal of Economics and Finance 29, 418-440.

Balcilar, M., Demirer, R., 2015. Impact of Global Shocks and Volatility on Herd Behavior in an Emerging Market: Evidence from Borsa Istanbul. Emerging Markets Finance and Trade 51, $1-20$.

Balcilar, M., Demirer, R., Ulussever, T. 2017. Does speculation in the oil market drive investor herding in emerging stock markets? Energy Economics 65, 50-63.

Basher, S. Haug, A. A., Perry Sadorsky, P. 2012. Oil prices, exchange rates and emerging stock markets.Energy Economics 34, 227-240. 
Bernanke, B. 2016. The relationship between stocks and oil prices. Brookings. https://www.brookings.edu/blog/ben-bernanke/2016/02/19/the-relationship-between-stocksand-oil-prices/

Bikhchandani, S., Sharma, S. 2001. Herd behavior in financial markets: A review. IMF Staff Papers 47, 279-310.

Blasco, N., Corredor, P., \& Ferreruela, S. 2012. Does herding affect volatility? Implications for the Spanish stock market. Quantitative Finance, 12(2), 311-327.

Cakan, E., Balagyozyan, A. (2014). Herd behavior in the Turkish banking sector. Applied Economics Letters, 21(2), 75-79.

Chan, L. H. Nguyen, C. M, Chan, K. C., 2015. A new approach to measure speculation in the oil futures market and some policy implications. Energy Policy 86, 133-141

Chang, E. C., Cheng, J. W., \& Khorana, A. 2000. An Examination of Herd Behavior in Equity Markets: An International Perspective. Journal of Banking and Finance 24 (10), 16511699.

Chiang, T. C., Zheng, D. 2010. An empirical analysis of herd behavior in global stock markets. Journal of Banking \& Finance 34 (8), 1911-1921.

Christie, W. G. and Huang, R. D. 1995. Following the Pied Piper: Do individual Returns Herd around the Market? Financial Analyst Journal, July-August 1995, 31-37.

Demirer, R., Kutan, A. 2006. Does Herding Behavior Exist in Chinese Stock Market? Journal of International Financial Markets, Institutions and Money 16, 123-142.

Demirer, R., Kutan, A. \& Chen, C. 2010. Do Investors Herd in Emerging Stock Markets? Evidence from the Taiwanese Market. Journal of Economic Behavior \& Organization, 76, 283-295.

Demirer, R., Lien, D., and Zhang, H. 2015. Industry Herding and Momentum Strategies. Pacific-Basin Finance Journal 32, 95-110

Economou, F., Kostakis, A., \& Philippas, N. (2011). Cross-Country Effects in Herding Behaviour: Evidence from Four South European Markets. Journal of International Financial Markets, Institutions \& Money, 21, 443-460.

Froot, K., Scharfstein, D., Stein, J., 1992. Herd on the street: Informational inefficiencies in a market with short-term speculation. Journal of Finance, 47, 1461-1484.

Issac, M.J., and Ratti, R.A., (2009). Crude Oil and stock markets: Stability, instability, and bubbles. Energy Economics. 31, 559-568.

Jones, D.W., Lelby, P.N., Paik, I.K., 2004. Oil price shocks and the macroeconomy: What has been learned since 1996? Energy Journal 25, 1-32.

Kilian, L., 2008. The economic effects of energy price shocks. Journal of Economic Literature, 46, 871-1009.

Kilian, L., and Park, C. 2009. The impact of oil prices shocks and the U.S. stock market. International Economic Review 50, 1267-1287. 
Philippas, N., Economou, F., Babalos, V., \& Kostakis, A. 2013. Herding behavior in REITs: Novel tests and the role of financial crisis. International Review of Financial Analysis, 29, $166-174$.

Sukcharoen, K., Zohrabyan, T., Leatham, D., et al., 2014. Interdependence of oil prices and stock market indices: A copula approach. Energy Economics. 44(C), 331-339.

Tan, L., Chiang T. C., Mason, J. R., \& Nelling, E. (2008). Herding behavior in Chinese stock markets: An examination of A and B shares. Pacific-Basin Finance Journal 16, 61-77.

Yao, J., Ma, C., and He, W. P., 2014. Investor herding behaviour of Chinese stock market. International Review of Economics and Finance 29, 12-29. 